\title{
Outsourcing in contests
}

\author{
Frode Meland • Odd Rune Straume
}

Received: 20 June 2006 / Accepted: 19 September 2006 / Published online: 29 November 2006 (C) Springer Science + Business Media B.V. 2006

\begin{abstract}
We study ex post outsourcing of production in an imperfectly discriminating contest, interpreted here as a research tournament or a procurement contest for being awarded some production contract. We find that the possibility of outsourcing increases competition between the contestants, leading to higher total contest effort, if the contest winner is expected to obtain a sufficiently large share of ex post outsourcing rents. Under reasonable assumptions, outsourcing tends also to increase the number of active contestants, strengthening the case for outsourcing to increase total contest effort. If such effort is socially wasteful, outsourcing creates a welfare trade-off between ex ante and ex post efficiency.
\end{abstract}

Keywords Contests $\cdot$ Non-price competition $\cdot$ Outsourcing

JEL Classification: D44, L23, L24

\section{Introduction}

In many cases, competition between firms takes the form of a contest, where firms spend resources in order to win a contested "prize". In this paper, we analyze a situation where the allocation of a production contract is determined in an imperfectly discriminating contest, where a given number of potential suppliers exert sunk effort in order to increase the probability of being awarded the contract. The novel contribution of the paper is that we allow for the possibility of ex post horizontal outsourcing of production. ${ }^{1}$ We analyze how

\footnotetext{
${ }^{1}$ Horizontal outsourcing, where inputs or parts of the final production of a good are subcontracted to rival firms within the same industry, is a common phenomenon in many industries (see, e.g., Kamien et al., 1989, Spiegel, 1993; Chen et al., 2004, for further discussions and examples).

F. Meland

Department of Economics, University of Bergen, Norway

O. R. Straume $(\bowtie)$

Department of Economics and NIPE, University of Minho, Portugal; Department of Economics, School of Economics and Management, University of Minho, Campus de Gualtar, 4710-057 Braga, Portugal e-mail: o.r.straume@eeg.uminho.pt
} 
such outsourcing possibilities affect competition between firms in the contest for the prime contract, and we also discuss implications for social welfare.

There are several general examples of firm competition that fit our contest set-up. Consider competition for big projects or large-scale production contracts in the public procurement business, where the final allocation of the contract may crucially depend on different types of sunk effort undertaken by competing suppliers in order to influence the buyer's decision. For example, a potential supplier might undertake investments in order to improve the quality of his product and tailoring it to match the buyer's needs and requirements, thereby increasing the probability of being awarded the contract. ${ }^{2}$ Furthermore, firms may also spend considerable resources on lobbying - even direct bribes - in order to secure lucrative licences or contracts. ${ }^{3}$ Since contracts might not be awarded to the most cost-efficient firm, there could be ex post incentives for horizontal outsourcing of production to firms with lower production costs. ${ }^{4}$ Some striking anecdotal examples can be found in the clean-up and reconstruction process after Hurricane Katrina in the US, where critical questions have been raised about a number of no-bid and limited-bid contracts which were given to prime contractors that have allegedly earned excessive profits by subsequently subcontracting the work. ${ }^{5}$

Another fitting example is $R \& D$ tournaments, where firms spend resources on $R \& D$ in order to obtain a profitable patent, licence or production contract. ${ }^{6}$ An illustrative specific example is US defense procurement, where the "prizes" of research contests held by the Department of Defense are profitable production contracts. Thus, the regulatory structures applies well to the rent-seeking framework of a contest, as also argued by Rogerson (1989). Furthermore, this industry is also characterized by a large extent of post-award subcontracting between firms who were rivals in competition for prime contracts (see, e.g., Alexander, 1997).

How is the possibility of ex post outsourcing likely to affect firms' choice of contest effort? Outsourcing tends to increase effort incentives for high-cost firms, due to reduced effective production costs, while the most efficient firm has reduced incentives, since this firm will expect to appropriate part of the contested prize through ex post subcontracts in any case. The relative strength of these two effects depends on the expected allocation of ex post outsourcing rents. More specifically, we find that the possibility of outsourcing will increase total contest effort if the contest winner obtains a sufficiently large share of these rents. Outsourcing tends also to increase the number of active contestants, strengthening the case for outsourcing to increase contest effort. These results shed some new light on the common view of horizontal subcontracting as a collusive device. ${ }^{7}$ Collusion is not an

\footnotetext{
${ }^{2}$ One specific example is operating licences (e.g., in the telecommunications sector) that are awarded in socalled beauty contests, based on the contestants proposed plans to meet certain quality standards, where (some or all) of the actual services can be subcontracted.
}

${ }^{3}$ See, e.g., Konrad (2000) for a further discussion.

${ }^{4}$ Clark and Riis (2000) study allocative efficiency in bribery contests for government contracts. Ex post outsourcing of the contract is not an issue, though.

${ }^{5}$ Perhaps one of the most controversial cases is the $\$ 40$ million contract given to the Alaskan-owned company Akima Site Operations for the supply of 450 portable classrooms in Mississippi. The company had allegedly not been involved in similar activity before and, therefore, had to rely on subcontracting. The controversy has been further spurred by the strong lobbying connections of Akima's parent company Nana (see, e.g., Lipton, 2005).

${ }^{6}$ See, e.g., Taylor (1995) and Fullerton and McAfee (1999).

${ }^{7}$ In a standard oligopoly model of international trade, Chen et al. (2004) find that horizontal outsourcing has a collusive effect that could raise prices, while Alexander (1997) argues that subcontracts may help facilitate collusive bidding in prime contract auctions. In a framework of strategic outsourcing - though vertical, rather 
issue in the present paper, but our results show that competition may actually increase from subcontracting between potential suppliers.

From a viewpoint of social welfare, though, increased competition for winning a contested prize might not always be desirable. In situations where a considerable amount of contest effort is resources spent on lobbying or bribes, a social planner might want to introduce measures - such as regulation on subcontracting - in order to reduce, for instance, the potential payoff of corrupt behavior by government officials. Where contest effort is wasteful, but not counter-productive, social welfare would depend on expected aggregate profits. What is then the effect of ex post outsourcing? If such outsourcing leads to increased effort and, thus, decreased profit, one might expect that the possibility of outsourcing is welfare detrimental. However, there is a trade-off between ex ante and ex post efficiency: Since high-cost firms may be awarded the contract if outsourcing is not allowed, outsourcing may increase aggregate firm profits, due to improved allocative efficiency, even though rent-seeking expenditures increase.

We also apply our model to discuss globalization and market integration between high- and low-cost countries. Consider, for example, the entry of foreign (low-cost) firms to an R\&D contest. Is this necessarily detrimental to domestic (high-cost) firms, in terms of expected profits? Without outsourcing, the answer is yes. However, the possibility of outsourcing could very well improve ex post allocative efficiency to the point where domestic firms benefit (in expectation) from foreign competition. We elaborate on this point in the latter part of the paper.

To the best of our knowledge, ours is the only paper dealing with horizontal outsourcing in a contest framework. However, the present paper relates to several earlier contributions on horizontal outsourcing focusing on other modes of competition. Kamien et al. (1989) analyze how the possibility of ex post subcontracting affects the initial competition for a contract in a duopoly under price competition, where the incentive for outsourcing stems from strictly convex production costs. Particular attention is directed towards two polar cases, where either the winner or the loser of the initial contract dictates the terms of the subcontract, and the authors find that competition is higher in the former case. An equivalent result is derived in the present paper, although the framework is quite different.

Spiegel (1993) analyses a duopoly situation which is quite similar to Kamien et al. (1989), the important difference being that firms are assumed to compete in quantities rather than prices. ${ }^{8}$ As in our model, but in contrast to Kamien et al. (1989), incentives for subcontracting arise from cost asymmetries. Spiegel (1993) finds that ex post outsourcing is more likely to increase social welfare if the subcontractor's share of the outsourcing surplus is relatively small.

Another related paper is Gale et al. (2000), who consider a sequential auction for multiple contracts with ex post subcontracting possibilities between the initial bidders. Once more, outsourcing incentives arise because of cost asymmetries. The authors find that the possibility of ex post outsourcing might make the sellers worse off ex ante. Although the framework is quite different from ours, this result reflects a situation with low bargaining strength for the subcontractor in our model, where we show that outsourcing might reduce ex ante aggregate profits.

than horizontal - Shy and Stenbacka (2003) and Buehler and Haucaup (2006) all find that outsourcing generally softens competition.

${ }^{8}$ Chen et al. (2004) also study horizontal outsourcing under Cournot competition, but in a specific context of international trade. 
The rest of the paper is organized as follows. In the next section we present the benchmark model without outsourcing - a standard fixed-prize Tullock contest with asymmetric valuations. In Section 3 we introduce the possibility of ex post outsourcing and analyze the effects of outsourcing on contest effort under general assumptions about outsourcing prices, which include some easily interpretable scenaria as special cases. In Section 4 we analyze and discuss some welfare implications - and interpretations - of our results, while Section 5 concludes the paper.

\section{A benchmark model}

There are $n$ firms participating in a contest for being awarded a contract for the supply of a good with a gross value of $V$. Alternatively, the set-up can be thought of as an R\&D tournament, with $n$ firms competing to obtain a patent, license, production contract or simply a technological lead, which generates a revenue of $V$. We assume initially that the firm that wins the contest must supply the good by producing it in-house. The firms are different with respect to cost efficiency in production, implying that their valuation of the contested prize also differ. The net valuation for firm $i$ is given by

$$
V_{i}=V-c_{i}, \quad i=1, \ldots, n .
$$

where $c_{i}$ is firm $i$ 's cost of producing the good. We rank the contestants according to their net valuations, so that $c_{i}<c_{i+1}$, or $V_{i}>V_{i+1} \cdot{ }^{9}$

The probability of being awarded the prize depends on the relative up-front efforts of the contestants. Applying a standard Tullock framework ${ }^{10}$ the probability that firm $i$ wins the contest is given by

$$
P_{i}=\frac{x_{i}}{S_{n}}
$$

where $x_{i}$ is firm $i$ 's effort (in monetary terms), while $S_{n}:=\sum_{j=1}^{n} x_{j}$ is total effort exerted by all active contestants. ${ }^{11}$ Expected profits for firm $i$ are thus given by

$$
\pi_{i}=P_{i} V_{i}-x_{i}
$$

The first-order conditions for profit maximization define individual efforts as

$$
x_{i}=S_{n}\left(1-\frac{S_{n}}{V_{i}}\right)
$$

Contest effort is monotonically increasing in net valuation for each player. In our setting, this means that low-cost firms exert more effort than high-cost firms. By summing over $n$ and

\footnotetext{
${ }^{9}$ Net valuations are assumed to be common knowledge.

${ }^{10}$ See Tullock (1980).

${ }^{11}$ This success function also arises from the more elaborate probability structure presented in Fullerton and McAfee (1999). Baye and Hoppe (2003) establish the strategic equivalence between the Tullock model and a variety of research tournaments and patent race games.
} 
rearranging (4), assuming that all $n$ firms actively participate in the contest, we can derive total effort in equilibrium:

$$
S_{n}=\left(\frac{n-1}{n}\right) \widetilde{V}_{n},
$$

where $\widetilde{V}_{n}:=n\left(\sum_{j=1}^{n} \frac{1}{V_{j}}\right)^{-1}$ is the harmonic mean of the $n$ firms' valuations of the contested prize.

It remains to ensure that all $n$ agents will actually choose to participate in the contest. From (4) it is easily seen that $x_{i} \geq 0$ only for $V_{i} \geq S_{n}$, thus the number of contestants in a free entry equilibrium is the $n$ lowest-cost firms, where $n$ is the highest integer that satisfies the following condition: ${ }^{12}$

$$
V_{n} \geq S_{n}=\left(\frac{n-1}{n}\right) \tilde{V}_{n}
$$

From (6) it follows, as noted by Stein (2002), that total effort is always lower than the valuation of the active player with the lowest valuation of the prize. ${ }^{13}$

\section{Outsourcing}

We now depart from the standard set-up of the previous section to allow for ex post outsourcing of the awarded prize. More specifically, the winner of the contest can subcontract, or outsource, some or all of the post-contest production activities to one of its competitors. A realistic scenario would be that only parts of the total production is outsourced (e.g., production of some parts and components). Here, we assume - like Kamien et al. (1989) do - that the winner can outsource the entire production of the good. This assumption is only made for analytical clarity and does not qualitatively affect the main workings of the model.

In this model, incentives for ex post outsourcing arise from cost differences in production. Thus, unless the lowest-cost firm (i.e., firm 1) wins the contest, there will always be an incentive for ex post outsourcing. In the following, when analyzing the effects of ex post outsourcing, we make the fundamental assumption that outsourcing is always efficient; that is, the good will always be produced by firm 1. Furthermore, to keep the analysis as general as possible, we assume that, if the contest is won by firm $i>1$, the contest winner subcontracts production of the good to firm 1 for a price $z_{i} \in\left[c_{1}, c_{i}\right]{ }^{14}$

With this assumption, all except the lowest-cost firm maximize

$$
\pi_{i}=P_{i}\left(V-z_{i}\right)-x_{i}, \quad i=2, . ., n .
$$

Thus, if $z_{i}<c_{i}$, the possibility of ex post outsourcing increases the incentives for high-cost firms to exert effort in the contest. This applies even to firms with very high production costs, which would otherwise not have participated in the contest.

\footnotetext{
${ }^{12}$ Following the procedure of Hillman and Riley (1989), it is easily checked that for $V_{n+1}<S_{n}$, the $n+1$ 'th firm does not have any incentives to join the contest.

${ }^{13}$ For a further discussion of equilibrium existence, see, e.g., Fullerton and McAfee (1999).

${ }^{14}$ The outsourcing prices $z_{i}$ are assumed to be ex ante common knowledge.
} 
Firm 1 is different since it also receives a non-negative payoff if other firms win. Firm 1 gets paid $z_{i} \geq c_{1}$ to produce the good for another firm if that firm wins the contest. Expected payoffs for firm 1 are thus

$$
\pi_{1}=P_{1}\left(V-c_{1}\right)+\sum_{i=2}^{n} P_{i}\left(z_{i}-c_{1}\right)-x_{1}
$$

which can be re-arranged to

$$
\pi_{1}=P_{1} V+\sum_{i=2}^{n} P_{i} z_{i}-c_{1}-x_{1}
$$

As long as $z_{i}>c_{1}$, firm 1 also gets a positive payoff from others winning the contest. Accordingly, firm 1 has a lower incentive to exert effort to win the contest, compared with the benchmark case without the possibility of outsourcing. ${ }^{15}$

The first-order conditions for optimal individual efforts in the contest are easily derived from (7) and (8):

$$
\begin{aligned}
& \frac{\partial \pi_{i}}{\partial x_{i}}=\frac{S_{n}-x_{i}}{S_{n}^{2}}\left(V-z_{i}\right)-1=0, \quad i=2, \ldots, n . \\
& \frac{\partial \pi_{1}}{\partial x_{1}}=\frac{S_{n}-x_{1}}{S_{n}^{2}} V-\frac{1}{S_{n}^{2}} \sum_{i=2}^{n} x_{i} z_{i}-1=0,
\end{aligned}
$$

By some manipulations of the first-order conditions, we derive a relatively simple expression for total contest effort under outsourcing:

$$
S_{n}^{o}=\frac{1}{n}\left((n-1) V-\sum_{i=2}^{n} z_{i}\right) .
$$

The participation constraint is equivalent to the benchmark case. Firm $n$ will enter the contest if $V-z_{n} \geq S_{n}^{o}$. The number of contestants in a free entry equilibrium is the $n$ lowest-cost firms ${ }^{16}$, where $n$ is the highest integer that satisfies the condition

$$
V \geq n z_{n}-\sum_{i=2}^{n} z_{i} .
$$

Our first result, which will be used later, follows straightforwardly from (11):

Proposition 1. With the possibility of ex post outsourcing, total contest effort is decreasing in all outsourcing prices $z_{i}$.

\footnotetext{
${ }^{15}$ Even though outsourcing reduces the effort incentives of firm 1, this firm always stays active. For the case of a fully discriminatory contest, Konrad (2006) finds that cross firm shareholdings may make the ex ante best firm abstain from bidding altogether.

16 "Lowest-cost" now refers to lowest cost under outsourcing. Firms may thus be ranked differently with and without outsourcing.
} 
There is a monotonic relationship between outsourcing prices and effort incentives in the contest. A reduction of $z_{i}$ will increase firm $i$ 's incentive to win the contest, since it will obtain a larger share of the ex post outsourcing rent. Furthermore, a reduction of $z_{i}$ also increases firm 1's incentive to win the contest, since the expected terms of the subcontract will be worse - from firm 1's viewpoint - if firm $i>1$ wins the contest. Consequently, a decrease in $z_{i}$ will increase effort incentives for both firm 1 and firm $i>1$.

3.1 Does the possibility of ex post outsourcing increase total contest effort?

For now we will assume that there is a fixed number $n$ of potential contestants, where $n$ is sufficiently low to satisfy the participation constraint with and without outsourcing - (12) and (6) - respectively. The effect of outsourcing on contest effort is crucially dependent on the outsourcing prices. Let us first consider the two polar cases of, respectively, $z_{i}=c_{1}$ and $z_{i}=c_{i}$.

\section{The contest winner obtains all outsourcing rents: $z_{i}=c_{1}$}

By inserting $z_{i}=c_{1}$ in (11), total contest effort is given by

$$
\left.S_{n}^{o}\right|_{z_{i}=c_{1}}=\frac{n-1}{n}\left(V-c_{1}\right)
$$

A comparison with the benchmark case, (5), yields the following result: ${ }^{17}$

Proposition 2. For a given number of contestants, the possibility of ex post outsourcing always increases total contest effort if the contest winner obtains all outsourcing rents.

The intuition follows from the first-order effects of outsourcing. Firm 1's effort incentives are unaffected by outsourcing, since the contest winner obtains all outsourcing rents, but all remaining contestants have higher effort incentives, since the net valuations of the contested prize are increased through the possibility of outsourcing.

\section{The contest winner obtains no outsourcing rents: $z_{i}=c_{i}$}

By inserting $z_{i}=c_{i}$ in (11), total contest effort in this scenario is given by

$$
\left.S_{n}^{o}\right|_{z_{i}=c_{i}}=\frac{1}{n} \sum_{i=2}^{n} V_{i} .
$$

A comparison with the benchmark case, (5), yields the following result:

Proposition 3. For a given number of contestants, the possibility of ex post outsourcing always reduces total contest effort if the contest winner obtains no outsourcing rents.

Once more, the intuition follows from the first-order effects of outsourcing. Effort incentives are unaffected for all firms $i>1$, but firm 1 has lower incentives to win the contest, since it can obtain part of the contested prize from a profitable subcontract in any case. This

${ }^{17}$ All non-trivial proofs are given in the Appendix. 
effect always outweighs the second-order effects resulting from a more symmetric contest (which generally leads to higher total effort).

Since Proposition 1 establishes the monotonicity between $S_{n}^{o}$ and $z_{i}$, it follows from Propositions 2 and 3 that there exists vectors of outsourcing prices, $\hat{z}=\left(\hat{z}_{2}, \ldots, \hat{z}_{n}\right)$, such that $S_{n}^{o}>S_{n}$ if $z<\hat{z}$. We can thus state the following necessary and sufficient condition when describing the effect of outsourcing on contest effort:

Corollary 1. For a given number of contestants, the possibility of ex post outsourcing always increases (reduces) total contest effort if the contest winner obtains a sufficiently large (small) share of outsourcing rents.

A plausible interpretation is that outsourcing prices - and thus the distribution of outsourcing rents - are determined in bargaining between the contest winner and the subcontractor. Assuming bilateral Nash bargaining, the outsourcing price would be given by

$$
z_{i}=\beta_{i} c_{1}+\left(1-\beta_{i}\right) c_{i},
$$

where $\beta_{i}$ is firm $i$ 's relative bargaining strength. Corollary 1 then translates straightforwardly to the condition that outsourcing increases total contest effort if the contest winner has sufficient bargaining power. ${ }^{18}$

\subsection{A uniform outsourcing price}

Let us also consider another special case, namely a uniform outsourcing price $z_{i}=\bar{z} \in$ $\left[c_{1}, c_{2}\right]$. The upper bound $c_{2}$ on the uniform outsourcing price is necessary to comply with the assumption that outsourcing is always efficient. ${ }^{19}$

A striking feature of this special case is that the contest becomes fully symmetric. This can easily be seen by inserting $z_{i}=\bar{z}$ into the profit functions (7)-(8), yielding

$$
\begin{aligned}
& \pi_{1}=P_{1}(V-\bar{z})+\bar{z}-c_{1}-x_{1}, \\
& \pi_{i}=P_{i}(V-\bar{z})-x_{i}, \quad i=2, \ldots, n .
\end{aligned}
$$

With a uniform outsourcing price, it comes as no surprise that all firms $i>1$ have exactly the same effort incentives. Outsourcing increases the net valuations of the prize for these firms, since effective production costs decrease from $c_{i}$ to $\bar{z}$. Furthermore, firm 1 also chooses effort in the contest as if it has production costs equal to $\bar{z}$, as indicated by (15). Thus, with a uniform outsourcing price, the increase in effort incentives for firms $i>1$ and the decrease

\footnotetext{
${ }^{18}$ If we assume that only a fraction $\alpha_{i}$ of the production of firm $i$ could be outsourced, then the first order conditions for firms $i \geq 2$ (under bargaining) would be the same as under full outsourcing, only replacing $\beta_{i}$ with $\alpha_{i} \beta_{i}$. The same is not true for firm 1 , but it is easily shown that the incentives to exert effort is never lower than what is the case if we substituted $\alpha_{i} \beta_{i}$ for $\beta_{i}$. Corollary 1 could then be extended to include both bargaining strength and outsourcing share, where more of both would increase the likelihood of increased contest effort.

${ }^{19}$ If firm 2 wins the contract, there would be no outsourcing if $\bar{z}>c_{2}$, which contradicts the assumption of efficient outsourcing.
} 
in effort incentives for firm 1 are offsetting to the point where the contest becomes perfectly symmetric. Thus, a symmetric equilibrium exists and is given by ${ }^{20}$

$$
x_{i}=\left(\frac{n-1}{n^{2}}\right)(V-\bar{z}),
$$

which yields equilibrium total contest effort

$$
S_{n}=\left(\frac{n-1}{n}\right)(V-\bar{z})
$$

Summarizing:

Proposition 4. With a uniform outsourcing price, the possibility of ex post outsourcing implies that all contestants exert the same level of effort in the contest.

It follows from Proposition 4 that ex post outsourcing with a uniform outsourcing price levels the playing field completely with respect to the contest, and cost differences between firms do not affect the probability of winning. Furthermore, with respect to expected profits, only the production costs of the most cost-efficient firms matter. For firms $i>1$, relative cost efficiencies are effectually irrelevant.

\section{Example: Price competition for the subcontract: $\bar{z}=c_{2}$}

The most obvious interpretation of a uniform outsourcing price would be the equilibrium price that arises if the contest winner can outsource production by engaging the losing firms in price competition for the subcontract. In this case, the equilibrium price for the subcontract is (marginally below) $c_{2}$, and outsourcing is efficient (i.e., firm 1 produces the good in all cases).

How does the possibility of outsourcing affect total contest outlays in this example? With a fixed number of contestants, the effect of outsourcing on total effort is determined by how much firm 1 reduces its effort relative to how much the other firms may increase their effort. This, in turn, depends on the number of contestants and the distribution of net valuations. Inserting $\bar{z}=c_{2}$ in (18), a straightforward comparison with (5) produces the following result:

Proposition 5. With $n$ contestants, ex post outsourcing with price competition increases total contest effort if $V_{2}>\widetilde{V}_{n}$.

For $n=2$, the net valuation of firm 2 must necessarily be lower than the harmonic mean of the two players' valuations. In this case, the net effect is simply that firm 1 has a lower incentive to win the contest (i.e., firm 1 behaves as if it has a lower net valuation), while

${ }^{20}$ The result that ex post outsourcing with a uniform outsourcing price leads to a perfectly symmetric contest holds also for a more general contest success function of the form $P_{i}=\frac{x_{i}^{r}}{\sum_{j=1}^{n} x_{j}^{r}}$. Contrary to the asymmetric cases, closed form solutions for the equilibrium may then be obtained also for $r \neq 1$. 
the objective function of firm 2 remains constant. ${ }^{21}$ Accordingly, total effort drops. ${ }^{22}$ For $n>2$, however, the effect on total outlays is a priori ambiguous, and determined by the condition given in Proposition 5. It is possible, though, to say something general about the effect of the number of contestants, $n$. By applying the entry condition in the benchmark contest without outsourcing, we see that $\widetilde{V}_{n}$ is decreasing in $n$. It follows that a larger number of contestants will increase the probability that outsourcing leads to higher total effort in the contest. This also makes intuitive sense, since a higher number of contestants implies that there are more high-cost firms that have increased incentives to exert effort in the contest due to the possibility of ex post outsourcing.

\subsection{Entry}

So far we have analyzed the effect of ex post outsourcing on effort incentives under the assumption of a fixed number of contestants. However, the possibility of outsourcing is also likely to affect entry into the contest. The participation constraint in (12) is equivalent to the following entry constraint (see Footnote 12) for firm $n+1$ :

$$
V_{n+1} \leq S_{n}
$$

Note that entry always increases total effort. ${ }^{23,24}$

The entry incentives of firm $n+1$ when outsourcing is allowed/possible relative to the case where it is not, depend on two issues: Does outsourcing lead to higher or lower contest effort, and what happens to firm $n+1$ 's net valuation of the contest prize?

Since the net valuation of the contest prize never decreases with outsourcing, we can immediately conclude that whenever outsourcing leads to lower total contest effort for a given number of firms, entry incentives are increased. This weakens the result that outsourcing may result in lower total effort.

In the opposite case, when, for a given number of firms, contest effort increases as a result of outsourcing, a potential ambiguity appears. However, contest effort increases as a result of outsourcing precisely when and because high-cost firms obtain a higher net valuation of the contest prize (the contest winner obtains a high share of the outsourcing rents). It

${ }^{21}$ With only two players, price competition for the subcontract is equivalent to one of the games considered by Kamien et al. (1989), where the terms of the subcontract is determined by the loser of the initial contract.

${ }^{22}$ From (5) we can easily derive the effect of a change in one player's valuation on total effort in the contest. This is given by

$$
\frac{\partial S_{n}}{\partial V_{i}}=\frac{S_{n}^{2}}{(n-1) V_{i}^{2}}>0 .
$$

${ }^{23}$ Consider a situation with $n$ firms; $S_{n}=\frac{n-1}{\sum_{i=1}^{n} \frac{1}{V_{i}}}$. If firm $n+1$ enters, it has $V_{n+1}>S_{n}$, implying

$$
\begin{aligned}
S_{n+1} & =\frac{n}{\sum_{i=1}^{n} \frac{1}{V_{i}}+\frac{1}{V_{n+1}}}>\frac{n}{\sum_{i=1}^{n} \frac{1}{V_{i}}+\frac{1}{\frac{n-1}{\sum_{i=1}^{n} \frac{1}{V_{i}}}}} \\
& =\frac{n-1}{\sum_{i=1}^{n} \frac{1}{V_{i}}}=S_{n} .
\end{aligned}
$$

${ }^{24}$ We implicitly assume that entry of new contestants does not affect the expected terms of the subcontract in the outsourcing subgame (i.e., the expected net valuations) for "incumbent" contestants. 
is of course possible that the $n$ incumbent firms are very good at bargaining with the most efficient firm, while a potential entrant does much worse in this respect. Without entry, the possibility of outsourcing then yields higher total effort and a relatively low increase in the potential entrant's net valuation of the contested prize. Entry incentives may then decline. However, without such an asymmetry between potential entrants and incumbents - and since efforts increase precisely because high-cost firms have stronger incentives to exert effort - entry would typically lead to even higher effort, and not less. An example of this would be the case of a uniform outsourcing price, where the contest becomes perfectly symmetric and, consequently, free entry leads all potential entrants wanting to participate in the contest. ${ }^{25}$ In any case, even though we cannot preclude the fact that outsourcing may decrease entry incentives, the following conclusion still holds (since an ambiguity only appears when outsourcing actually leads to higher total effort):

Proposition 6. Compared with the benchmark case of no outsourcing, free entry makes it more likely that outsourcing yields higher contest effort.

An example is price competition for the outsourcing contract. It is in this case possible to show that with an infinite number of potential entrants, total effort always increases when outsourcing is allowed. Another interesting implication is that firms that are not able profitably to produce the good themselves have incentives to participate in the contest if they can outsource production to a lower-cost firm ex post.

\section{Some welfare considerations}

Optimal contest design is beyond the scope of this paper. We restrict attention to R\&D contests, bribery/lobbying games and other types of contests that arise, not through careful design, but more or less naturally. Could there still be a design element worth discussing? Whether or not outsourcing is being used to fulfill a production contract, should be relatively easy to monitor for the proper authorities. According to our results, a general ban on outsourcing in public contracting could have an impact on bribery and lobbying efforts. Often, these are seen as unwanted and even counter-productive, so reducing such efforts should be a goal for authorities seeking to align the public servants' incentives with public interest. Due to the ambiguity of our results, we cannot provide a clear-cut answer to whether outsourcing should be allowed or disallowed for the purpose of reducing incentives for bribery. We feel, however, that this is interesting in its own right: On the surface, it may seem intuitive that allowing outsourcing increases the profitability of corruptive behavior by firms, but what has to be remembered is that some firms - the ones most efficient in actually producing the contracted good - may engage in less corruptive behavior since they will obtain some of the surplus in any case.

Outright criminal activities like bribery aside, contest effort might still be of the type that is considered, if not counter-productive, then at least socially wasteful to a certain extent, with lobbying for government contracts as a natural example. Even in $R \& D$ contests, long patent protection or licensing periods (i.e., high prizes) may induce inefficiently high levels of effort. Is the possibility of ex post outsourcing likely to be socially beneficial if we abstract from any counter-productive issues and consider effort simply to be socially wasteful? Outsourcing

${ }^{25}$ Inserting $z_{i}=\bar{z}$ in (12), we can easily see that firm $n+1$ will enter the contest if $V>\bar{z}$, which is, by assumption, always true. 
improves ex post allocative efficiency, which is unambiguously positive from a welfare perspective. However, it may also increase incentives for socially wasteful effort.

We can capture this trade-off in a two-firm example with $\bar{z} \in\left[c_{1}, c_{2}\right]$. It is here illustrative to use the bargaining interpretation of Section 3.1, where we assume that $\bar{z}=\beta c_{1}+(1-\beta) c_{2}$, and $\beta$ is the contest winner's relative bargaining strength. With socially wasteful effort, welfare is given by expected aggregate profits. Without outsourcing, individual and total contest efforts, respectively, are given by (4) and (5), yielding expected aggregate profits

$$
\sum_{i=1}^{2} \pi_{i}=\frac{V\left(V-c_{1}-c_{2}\right)+c_{1}^{2}+c_{2}^{2}-c_{1} c_{2}}{2 V-c_{1}-c_{2}} .
$$

On the other hand, with ex post outsourcing and two firms (making the outsourcing price 'uniform'), the contest becomes perfectly symmetric (Proposition 5). Total effort is given by (18), with $n=2$ and $\bar{z}=\beta c_{1}+(1-\beta) c_{2}$, while expected aggregate profits are

$$
\sum_{i=1}^{2} \pi_{i}^{o}=\frac{1}{2}\left[V-c_{1}+(1-\beta)\left(c_{2}-c_{1}\right)\right] .
$$

Comparing the two cases, outsourcing is socially beneficial if

$$
\sum_{i=1}^{2}\left(\pi_{i}^{o}-\pi_{i}\right)=\frac{\left(c_{2}-c_{1}\right)}{2}\left[\frac{3\left(V-c_{2}\right)}{2 V-c_{1}-c_{2}}-\beta\right]>0 .
$$

For the special case of $\beta=0$, where the most efficient firm dictates the terms of the subcontract, the possibility of ex post outsourcing unambiguously improves social welfare. Wasteful effort is reduced, due to the reduced effort incentives of the most efficient firm, and ex post allocative efficiency is improved.

However, outsourcing is less likely to be socially beneficial the higher is $\beta$. The reason is that a higher level of $\beta$ increases incentives for socially wasteful effort when ex post outsourcing is a possibility. More bargaining strength to the least efficient firm increases this firm's net valuation of winning the contest, with a corresponding stronger incentive to exert effort. At the same time, the low-cost firm also gets a stronger incentive to win the contest, since a higher $\beta$ implies that the subcontract becomes less profitable for this firm if it does not win the contest.

From (22) we see that outsourcing will in fact reduce expected aggregate profits for sufficiently high levels of $\beta$ if

$$
\frac{3\left(V-c_{2}\right)}{2 V-c_{1}-c_{2}}<1,
$$

which can be expressed as

$$
V-c_{2}<c_{2}-c_{1} .
$$

In words, this condition states that the net valuation of the high-cost firm in the absence of outsourcing must be lower than the cost difference between the firms. If this is the case, the high-cost firm has low incentives to exert effort in the contest, absent outsourcing, relative to the low-cost firm. Thus, the probability that the most efficient firm will win the contest 
anyway is relatively high. This implies, in turn, that the improved allocative efficiency due to outsourcing is relatively moderate, and outweighed by the effect of increased total effort for sufficiently high level of $\beta$. Thus if $V-c_{2}<c_{2}-c_{1}$, there exists a critical value $\beta^{*}<1$ such that outsourcing is socially detrimental if $\beta \in\left(\beta^{*}, 1\right)$.

\subsection{Market integration}

Our analysis can also be interpreted in a context of globalization and market integration between high- and low-cost countries. Market integration does not meet favour in all circles. When China and other low-cost countries enter the global arena, many fear that Western companies will eventually lose ground and that the workers of Western economies face an uncertain future. However, while output market competition may become harder, depressing output prices, inputs typically also become cheaper. Which effect is more important? It is possible that Western firms and labor may endure and prosper, the latter if high-cost workers are able to qualify for lucrative jobs where they are not in direct competition with the low-cost workers of the expanding economies. ${ }^{26}$ In this section, we discuss a related topic: If low-cost firms from a foreign country are suddenly able or allowed to enter, say, an R\&D contest, how will this affect domestic profits?

Not surprisingly, without outsourcing, adding some low-cost firms to the contest can never be beneficial to high-cost firms. However, with outsourcing, the picture changes. While competition increases, reducing the probability that domestic firms win the contest, ex post allocative efficiency will also increase. It is easy to work out examples where the second effect dominates the first: Consider, for example, $n$ domestic firms with costs $c_{h}$ and $m$ foreign firms with costs $c_{l}<c_{h}$. Expected domestic profits are $\frac{1}{n}\left(V-c_{h}\right)$ if no foreign firms participate in the contest, and $n \frac{V-c_{l}}{(n+m)^{2}}$ if the $m$ foreign firms are participating, outsourcing is allowed and the contest winners obtain all outsourcing rents. In this case, total domestic profits increase if

$$
c_{h}>c_{l}+\frac{m(2 n+m)\left(V-c_{l}\right)}{(n+m)^{2}} ;
$$

that is, if allocative efficiency is sufficiently important.

Thus, market integration where low-cost firms enter the arena of high-cost firms may actually increase expected profits of the high-cost firms (and possibly national welfare as well) if the increased competition is accompanied by lowered production costs (in our case through the outsourcing option). This is before we include the possibility of additional profit opportunities (contests) that the high-cost producers may become eligible to take part in when markets are opened up in this way. ${ }^{27,28}$

\footnotetext{
${ }^{26}$ Lommerud et al. (2005) explore a variant of this question in a setting of international outsourcing in unionized industries.

${ }^{27}$ Meland (2002) discusses such market integration in a contest set-up with unionized labor.

${ }^{28}$ It may be noted that market integration can also change the way outsourcing rents are divided between contestants. For example, in a public procurement contest, the government might react to the entry of low-cost competitors by reducing $V$. This and other contest design issues are not discussed in this paper.
} 


\section{Concluding remarks}

We have analyzed the strategic effects and implications of ex post outsourcing in situations where competition between firms take on the characteristics of an imperfectly discriminating contest for profitable production contracts or licences. While horizontal outsourcing is often thought to facilitate collusion, we have shown that such arrangements might instead increase competition between firms, provided that the contest winner is expected to obtain a sufficient share of the ex post outsourcing rents. Whether or not such competition is desirable from a viewpoint of social welfare depends on the interpretation of the model. In a procurement contest, allowing outsourcing might increase the quality of the procured good, for example through higher R\&D investments by the contestants, but it might also increase incentives for lobbying and bribery.

\section{Appendix}

Proof of Proposition 2. By comparing (5) and (13), the possibility of outsourcing increases total contest effort if

$$
V_{1}-\frac{n}{\sum_{j=1}^{n} \frac{1}{V_{j}}}>0
$$

Since $V_{1}>V_{j}, j=2, \ldots, n$, it follows that $\sum_{j=1}^{n} \frac{1}{V_{j}}>\frac{n}{V_{1}}$. Thus,

$$
V_{1}-\frac{n}{\sum_{j=1}^{n} \frac{1}{V_{j}}}>V_{1}-\frac{n}{\frac{n}{V_{1}}}=0
$$

Q.E.D.

Proof of Proposition 3. By comparison of (5) and (14), the possibility of outsourcing reduces total contest effort if

$$
\sum_{i=2}^{n} V_{i} \sum_{i=1}^{n} \frac{1}{V_{i}}<n(n-1)
$$

In order to show that this inequality always holds, first note the following:

1. If a function $\left.f(\mathbf{x}) g(\mathbf{x})\right|_{g(\mathbf{x})=c}$, where $c$ is a constant, has a maximum $f\left(\mathbf{x}^{*}(c)\right) g\left(\mathbf{x}^{*}(c)\right)$, where $g\left(\mathbf{x}^{*}(c)\right)=c$, that is independent of $c$, then the function $f(\mathbf{x}) g(\mathbf{x})$ also has that maximum. That is, as long as we put restrictions on a function, but this does not affect the maximum value, then the maximum value of the function without the restriction must also be the same as with the restriction.

2. The participation constraints for the cases with and without outsourcing, respectively, can be rewritten as follows:

$$
\begin{gathered}
V_{n} \geq \frac{\sum_{i=2}^{n} V_{i}}{n} \Leftrightarrow V_{n} \geq \frac{\sum_{i=2}^{n-1} V_{i}}{n-1}, \\
V_{n} \geq \frac{n-1}{\sum_{i=1}^{n} \frac{1}{V_{i}}} \Leftrightarrow V_{n} \geq \frac{n-2}{\sum_{i=1}^{n-1} \frac{1}{\mathrm{~V}}} .
\end{gathered}
$$


Let us now apply pt. 1 above by defining the left-hand side of (A2) as follows:

$$
\Omega:=v \sum_{i=1}^{n} \frac{1}{V_{i}},
$$

where

$$
v:=\sum_{i=2}^{n} V_{i}
$$

is constant. Then we have

$$
\Omega:=v \sum_{i=1}^{n} \frac{1}{V_{i}}=v\left(\frac{1}{V_{1}}+\frac{1}{V_{2}}+\cdots+\frac{1}{v-V_{2}-V_{3}-\ldots-V_{n-1}}\right) .
$$

Assume first that $V_{1}$ is given. Assume also, for the sake of exposition, that the differences in net valuations hold with a weak inequality, i.e., $V_{i} \geq V_{i+1}$. What is the maximum value of $\Omega$ ? For $j \neq 1, n$ we have that

$$
\frac{\partial \Omega}{\partial V_{j}}=v\left(-\frac{1}{V_{j}^{2}}+\frac{1}{V_{n}^{2}}\right) \geq 0
$$

Thus, as long as $V_{j} \geq V_{n}, \Omega$ will never be reduced by increasing $V_{j}$. But $V_{j}$ is never higher than $V_{j-1}$. Similarly, $V_{j-1}$ is never higher than $V_{j-2}$. Thus, given $V_{1}$ and $v, \Omega$ is maximized if $V_{2}=V_{3}=\ldots=V_{n-1}=V_{1}$. Then, $V_{n}=v-(n-2) V_{1}$. Note also that the participation constraints reduce to

$$
\begin{gathered}
\left(\text { Outsourcing) } V_{n} \geq \frac{\sum_{i=2}^{n-1} V_{i}}{n-1}=\frac{n-2}{n-1} V_{1},\right. \\
\text { (No outsourcing) } V_{n} \geq \frac{n-2}{\sum_{i=1}^{n-1} \frac{1}{V_{i}}}=\frac{n-2}{n-1} V_{1} .
\end{gathered}
$$

Thus for the case of $V_{1}=V_{2}=\ldots=V_{n-1}$, the participation constraints under the outsourcing and no outsourcing regimes are the same.

Using $V_{n}=v-(n-2) V_{1}$, we have that

$$
\Omega=v\left(\frac{n-1}{V_{1}}+\frac{1}{v-(n-2) V_{1}}\right) .
$$

Can this value ever exceed $n(n-1)$ ? Assume that we can also change $V_{1}$. Which choice of $V_{1}$ maximizes $\Omega$ ?

$$
\frac{\partial \Omega}{\partial V_{1}}=v\left(-\left(\frac{n-1}{V_{1}^{2}}\right)+\frac{n-2}{V_{2}^{2}}\right) .
$$


It follows that

$$
\frac{\partial \Omega}{\partial V_{1}} \gtreqless 0 \Leftrightarrow V_{1} \gtreqless \frac{\sqrt{\frac{n-1}{n-2}} v}{1+(n-2) \sqrt{\frac{n-1}{n-2}}} .
$$

That is, the corner solutions are the candidates for maximum values. (If $V_{1}$ is small, $\frac{\partial \Omega}{\partial V_{1}}$ is negative; i.e., $\Omega$ is increased by reducing $V_{1}$. If $V_{1}$ is large, $\frac{\partial \Omega}{\partial V_{1}}$ is positive and the maximum value of $V_{1}$ yields the maximum value of $\Omega$.) Let us consider each of the two candidates in turn:

1. Given that $\frac{\partial \Omega}{\partial V_{1}}$ is negative, it is optimal to choose $V_{1}=V_{n}$, which implies $V_{1}=V_{2}=\ldots=$ $V_{n}=\frac{v}{n-1} \cdot{ }^{29}$ The maximum value of $\Omega$ is then

$$
\Omega^{\max 1}=v\left(\frac{n-1}{\frac{v}{n-1}}+\frac{1}{v-(n-2) \frac{v}{n-1}}\right)=n(n-1) .
$$

2. Given that $\frac{\partial \Omega}{\partial V_{1}}$ is positive, it is optimal to choose the highest possible $V_{1}$, and thus the lowest possible $V_{n}$. From the participation constraint, this implies $V_{n}=\frac{n-2}{n-1} V_{1}$. But we also have that $V_{n}=v-(n-2) V_{1}$. Solving these two equations yields

$$
\begin{aligned}
V_{1} & =v \frac{n-1}{n(n-2)}, \\
V_{n} & =\frac{v}{n} .
\end{aligned}
$$

Thus, ${ }^{30}$

$$
\Omega^{\max 2}=v\left(\frac{n-1}{v \frac{n-1}{n(n-2)}}+\frac{1}{\frac{v}{n}}\right)=n(n-1) .
$$

Accordingly, there are two maxima; one for $V_{1}=V_{2}=\ldots=V_{n}=\frac{v}{n-1}$, and one for $V_{1}=$ $V_{2}=\ldots=V_{n-1}=v \frac{n-1}{n(n-2)}$ and $V_{n}=\frac{v}{n}$. In both cases the restriction placed on $\sum_{i=2}^{n} V_{i}(v)$ determines the optimal values of $V_{i}$, but the maximum value of $\sum_{i=2}^{n} V_{i} \sum_{i=1}^{n} \frac{1}{V_{i}}$ is independent of $v$. Thus, the maximum value of $\sum_{i=2}^{n} V_{i} \sum_{i=1}^{n} \frac{1}{V_{i}}$ without this restriction is also $n(n-1)$. This maximum is reached only if we allow weak inequalities between the net valuations. It follows that, if we impose strict inequalities, i.e., $V_{i}>V_{i+1}$, the maximum value of $\sum_{i=2}^{n} V_{i} \sum_{i=1}^{n} \frac{1}{V_{i}}$ is always strictly lower than $n(n-1)$.

Q.E.D.

${ }^{29}$ This satisfies the participation constraints and also implies that $\frac{\partial \Omega}{\partial V_{1}}$ is actually negative:

$$
\frac{\partial \Omega}{\partial V_{1}}=-\frac{(n-1)^{2}}{v}
$$

${ }^{30}$ It is possible to show that these values of $V_{1}$ and $V_{n}$ are consistent with the assumption that $\frac{\partial \Omega}{\partial V_{2}}$ is positive. 
Acknowledgements We thank Kurt R. Brekke, Kjell Erik Lommerud, participants at the WZB Conference on "Advances in the Theory of Contests and Tournaments" (Berlin, October 2005), and two anonymous referees, for valuable comments.

\section{References}

Alexander, B.J. (1997). Mechanisms for rent transfers: Subcontracting among military aircraft manufacturers. Public Choice, 91, 251-269.

Baye, M.R., \& Hoppe, H.C. (2003). The strategic equivalence of rent-seeking, innovation, and patent-race games. Games and Economic Behavior, 44, 217-226.

Buehler, S., \& Haucap, J. (2006). Strategic outsourcing revisited. Journal of Economic Behavior \& Organization, forthcoming.

Chen, Y., Ishikawa, J., \& Yu, Z. (2004). Trade liberalization and strategic outsourcing. Journal of International Economics, 63, 419-436.

Clark, D.J., \& Riis, C. (2000). Allocation efficiency in a competitive bribery game. Journal of Economic Behavior \& Organization, 42, 109-124.

Fullerton, R.L., \& McAfee, R.P. (1999). Auctioning entry into tournaments. Journal of Political Economy, $107,573-605$.

Gale, I.L., Hausch, D.B., \& Stegeman, M. (2000). Sequential procurement with subcontracting. International Economic Review, 41, 989-1020.

Hillman A.L., \& Riley, J.G. (1989). Politically contestable rents and transfers. Economics and Politics, 1, $17-39$.

Kamien, M.I., Li, L., \& Samet, D. (1989). Bertrand competition with subcontracting. RAND Journal of Economics, 20, 553-567.

Konrad, K.A. (2000). Trade contests. Journal of International Economics, 51, 317-334.

Konrad, K.A. (2006). Silent interests and all-pay auctions. International Journal of Industrial Organization, forthcoming.

Lipton, E. (2005). Deal to replace schools after Katrina is faulted. New York Times, November 11, Section A, Page 1, Column 2.

Lommerud, K.E., Meland, F., \& Straume, O. R. (2005). Can deunionization lead to international outsourcing? CESifo Working Paper No. 1545.

Meland, F. (2002). Unions and market integration in contests. Public Choice, 112, 293-304.

Rogerson, W.P. (1989). Profit regulation of defense contractors and prizes for innovation. Journal of Political Economy, 97 1284-1305.

Shy, O., \& Stenbacka, R. (2003). Strategic outsourcing. Journal of Economic Behavior \& Organization, 50, 203-224.

Spiegel, Y. (1993). Horizontal subcontracting. RAND Journal of Economics, 24, 570-590.

Stein, W.E. (2002). Asymmetric rent-seeking with more than two contestants. Public Choice, 113, 325-336.

Taylor, C.R. (1995). Digging for golden carrots: An analysis of research tournaments. American Economic Review, 85, 872-890.

Tullock, G. (1980). Efficient rent-seeking. In J. Buchanan, R. Tollison, \& G. Tullock, (Eds.) Towards a theory of the rent-seeking society. A\&M University Press: College Station, Texas. 